OPEN ACCESS

Edited by:

Pierre J. Magistretti,

King Abdullah University of Science and Technology, Saudi Arabia

Reviewed by:

Silmar Teixeira,

Federal University of Piauí, Brazil Jong-Min Kim

Seoul National University Bundang Hospital, South Korea

${ }^{*}$ Correspondence:

Xiang Li

lix2009@126.com

Specialty section:

This article was submitted to Movement Disorders,

a section of the journal

Frontiers in Neurology

Received: 02 April 2019 Accepted: 08 October 2019 Published: 22 October 2019

Citation:

Wang W, Zeng F, Hu Y and Li X (2019) A Mini-Review of the Role of G/utamate Transporter in Drug Addiction. Front. Neurol. 10:1123. doi: 10.3389/fneur.2019.01123

\section{A Mini-Review of the Role of Glutamate Transporter in Drug Addiction}

\author{
Wenjun Wang ${ }^{1}$, Fancai Zeng ${ }^{2}$, Yingying $\mathrm{Hu}^{2}$ and Xiang $\mathrm{Li}^{2 *}$ \\ ${ }^{1}$ Institute for Cancer Medicine and School of Basic Medical Sciences, Southwest Medical University, Luzhou, China, \\ ${ }^{2}$ Department of Biochemistry and Molecular Biology, School of Basic Medical Science, Southwest Medical University, \\ Luzhou, China
}

Goals: The development of new treatment for drug abuse requires identification of targetable molecular mechanisms. The pathology of glutamate neurotransmission system in the brain reward circuit is related to the relapse of multiple drugs. Glutamate transporter regulates glutamate signaling by removing excess glutamate from the synapse. And the mechanisms between glutamate transporter and drug addiction are still unclear.

Methods: A systematic review of the literature searched in Pubmed and reporting drug addiction in relation to glutamate transporter. Studies were screened by title, abstract, and full text.

Results: This review is to highlight the effects of drug addiction on glutamate transporter and glutamate uptake, and targeting glutamate transporter as an addictive drug addiction treatment. We focus on the roles of glutamate transporter in different brain regions in drug addiction. More importantly, we suggest the functional roles of glutamate transporter may prove beneficial in the treatment of drug addiction.

Conclusion: Overall, understanding how glutamate transporter impacts central nervous system may provide a new insight for treatment of drug addiction.

\footnotetext{
Keywords: addiction, glutamate transporters, excitatory amino acid transporters, vesicular glutamate transporters, glutamate
}

\section{INTRODUCTION}

Drug addiction is a chronic and recurrent mental disorder characterized by compulsive and uncontrollable drug use and addiction behavior (1). There is growing evidence that drug abuseinduced changes in synaptic plasticity, especially in the midbrain dopamine system, lead to longterm effects and contribute to relapse after withdrawal (2). Drug addiction can also inhibit the central respiratory system and reduce the sensitivity of the respiratory center to carbon dioxide. Long-term use of addictive drugs can lead to pathological changes in the related brain areas and produce related pathological behavior, such as drug seeking, drug withdraw, and relapse. The molecular mechanisms of drug addiction are mainly involved in the following four brain regions: prefrontal cortex (PFC), ventral ventral tegmental area (VTA), nucleus accumbens (NAc), and hippocampus (Hip). After drug addiction, the pathological behavior and memory are closely related to these brain regions. In addition, the most important thing is that the pathological changes in these brain regions will change the neural projection of the brain and the synaptic plasticity of the 
neurons. The addiction of some drugs limited its clinical implication. For example, morphine is the first-line choice for the management of chronic pain in both cancer or noncancer patients (3-5). Dolantin is a synthetic opioid receptor agonist. Although dolantin has been used in the clinical treatment of pain instead of morphine, the analgesic effect of dolantin is about 10 percent of morphine. Beside that, chronic administration of dolantin also leads to addiction and tolerance. Therefore, it is necessary to investigate the mechanism of drug addiction. Recently, lots of studies have provided evidence for the complexity of anatomical and functional interactions between neuros in brain reward circuits prompted by drug's rewarding action, including dopaminergic neurons, glutamatergic neurons, and gama aminobutyric acid neurons. Recently research has reported that glutamatergic neurons is closely related to drug addiction, because it is involved in learning association in mesocorticolimbic reward circuitry. The PFC glutamatergic neurons projection to the NAc plays an important role in drug seeking behavior (6). NAc also receives glutamatergic input from Hip and VTA, which has been proved that this circuit is implicated in drug addiction (79). Cholinergic neurons from laterodorsal tegmental nucleus (LDTg) activate dopamine neurons in the reward circuit via projecting to the VTA (10). GABAergic neurons from NAc project to the VTA associating with rewarding by regulating DA neurons activity (11). Schematic of brain reward circuitry was shown in Figure 1. However, there is less research on glutamate transporters in drug addiction. Here, we review the glutamate transporters in brain reward circuits under drug addiction.

Glutamate transporters (GLT) play an important role in physiological glutamate homeostasis, neurotoxicity, and glutamatergic regulation of opioid tolerance (12-16). It has been found that there are two kinds of glutamate transporter, including vesicular glutamate transporters (VGLUTs) and excitatory amino acid transporters (EAATs) (17). Extracellular glutamate levels are regulated by high-affinity EAATs (18). EAATs are known to be responsible for maintaining the homeostasis of the extracellular glutamate concentration by protecting neurons against detrimental overstimulation of glutamatergic receptors (19). EAATs are classified into five different subtypes: glutamate aspartate transporter (EAAT1), glutamate transporter-1 (EAAT2), excitatory amino acid carrier-1 (EAAT3), EAAT4, and EAAT5 (20). In addition to the aforementioned mechanisms, glutamate concentrations are also regulated by modulating glutamate internalization into synaptic vesicles through VGLUTs 1, 2, and 3. The release of glutamate in the presynaptic area depends upon the expression and the function of secretory vesicles, vesicular glutamate transporters (VGLUTs). VGLUT family presents distinct expression patterns. VGLUT1 and VGLUT2 are the major secretory vesicles in the brain, and VGLUT3 often acts as a cotransporter of glutamate and other neurotransmitters, such as serotonin, gamma-aminobutyric acid (GABA), and acetylcholine (21). Tables 1, 2 provide a summary of the distribution of glutamate transporters and potential drug targets.

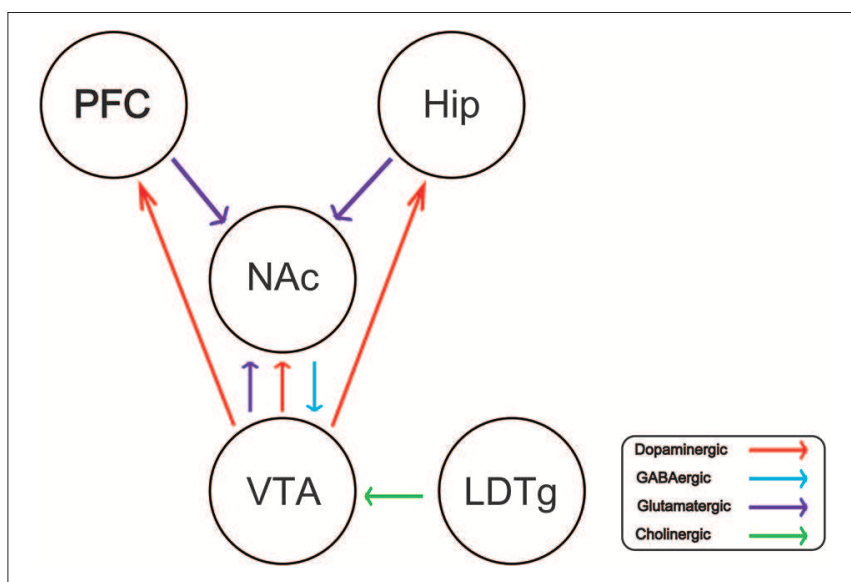

FIGURE 1 | Schematic of brain reward circuitry implicated in addiction. The ventral tegmental area (VTA) projects dopaminergic (red) transmission to the nucleus accumbens (NAc), hippocampus (Hip), prefrontal cortex (PFC). The NAc receives Glutamatergic (purple) inputs from the PFC, VTA, and Hip. The VTA receives GABAergic (blue) from the NAc. The VTA receives cholinergic (green) input from the laterodorsal tegmental nucleus (LDTg).

\section{METHODS}

This review is according to literature study in Pubmed until March 31st 2019. Pubmed was searched by using free-text terms and addiction subject heading. A uniform search strategy was applied to Pubmed to identify the reported studies. The primary and keywords were as following: addiction, withdrawal, relapse, reward VGLUT1, VGLUT2, VGLUT3, EAAT1, EAAT2, EAAT3, EAAT4, EAAT5, PFC, VTA, NAc, Hip, GLP, Glu, glutamate neuron, dopamine neuron, cholinergic interneurons, hippocampal neurons and neuroplasticity. All the studies were screened by title, abstract, and full text.

\section{The Role of GLT in Addiction in the VTA}

The VTA is a tiny area near the midbrain, which is involved reward effects (43-46). The VTA mainly contains three types of neurons: dopamine neurons make up about $60-65 \%$ of the cells in the VTA, GABAergic neurons make up $\sim 30-35 \%$ of the cells in the VTA, a population of glutamate neurons make up $\sim 2-$ $3 \%$ of the cells in the VTA (7). Yamaguchi et al. have proved that VGLUT2 mRNA but not VGLUT1 mRNA was expressed in the VTA (30). VTA glutamatergic neurons-expressing vesicular glutamate transporter2 (VGLUT2)-project to limbic and cortical regions, but also excite neighboring dopaminergic neurons (47). VGLUT2 was also found in dopaminergic neurons from VTA, which projects to NAc $(30,48)$. VGLUT2 exists in these neurons and allows glutamate to release from VTA dopaminergic neurons (49). This synergistic effect between glutamate and dopamine signaling may be important for the plasticity of postsynaptic AMPA receptors (50). Therefore, VTA plays an important role in drug addiction. Wang et al. suggested that photoactivation of VTA VGLUT2 neurons expressing Channelrhodopsin-2 (ChR2) under VGLUT2 promoter causes conditioned place preferences and also reinforces instrumental behavior. They also found that 
TABLE 1 | Distribution of vesicular glutamate transporters.

\begin{tabular}{|c|c|c|c|c|}
\hline $\begin{array}{l}\text { Types of } \\
\text { VGLUT }\end{array}$ & Majority distribution & Location & $\begin{array}{l}\text { Target for } \\
\text { addiction }\end{array}$ & References \\
\hline VGLUT1 & $\begin{array}{l}\text { Neocortex and } \\
\text { hippocampus (22) } \\
\text { Spinal cord (23) } \\
\text { Hypothalamus and } \\
\text { amygdala (24) } \\
\text { Prefrontal cortex (25) } \\
\text { Nucleus accumbens (26) } \\
\text { Striatum (27) } \\
\text { Cerebellum (28) }\end{array}$ & $\begin{array}{l}\text { Synaptic } \\
\text { vesicles }\end{array}$ & Potential & (29) \\
\hline VGLUT2 & $\begin{array}{l}\text { Ventral ventral tegmental } \\
\text { area (30) } \\
\text { Basolateral amygdala (31) } \\
\text { Nucleus accumbens (32) }\end{array}$ & $\begin{array}{l}\text { Synaptic } \\
\text { vesicles }\end{array}$ & Yes & (33) \\
\hline VGLUT3 & $\begin{array}{l}\text { Caudate-putamen, olfactory } \\
\text { tubercle } \\
\text { Nucleus accumbens } \\
\text { Hippocampus } \\
\text { Interpeduncular nucleus and } \\
\text { dorsal } \\
\text { Medial raphe nuclei (34) }\end{array}$ & $\begin{array}{l}\text { Synaptic } \\
\text { vesicles }\end{array}$ & Yes & (35) \\
\hline
\end{tabular}

activation of VTA VGLUT2 neurons is mediated by local AMPAR and NMDAR. In addition, VTA VGLUT2 neurons mediate the development of place preference by releasing glutamate into the VTA, resulting in activation of both NMDA and AMPA receptors (47). The loss of VGLUT2 expression in DA (dopamine) neurons in VTA probably leads to a decrease in excitatory activity of the affected dopaminergic neurons. VTA DA neurons mediate the rewarding effects of psychostimulants such as amphetamine by increasing the level of extracellular DA in limbic areas such as the NAc (51). Birgner et al. proved that DAT-Cre/Vglut2Lox mice attenuated behavioral response to amphetamine compared to the control mice (52). These findings suggested that VGLUT2 played an important role for mediating rewarding effects of drugs of addiction. Behavioral studies have proved that optogenetic activation of VTA VGLUT2 neurons or their axonal terminals elicit aversive $(47,53-55)$. Until now, the role of some other glutamate transporters in addiction has been poorly investigated. Therefore, it is necessary to detect the role of glutamate transporters in addiction.

\section{The Role of GLT in Addiction in the NAc}

The NAc is mainly composed of gamma-aminobutyric acid neurons. In addition, there are also Astrocyte cells and various types of Interneuron. The glutamate input to NAc mainly comes from the prefrontal cortex, thalamus, amygdala, and hippocampus. Different glutamate projections lead to different synapses and behavioral functions. The structure of NAc is complex, which can be divided into nucleus and shell regions according to its anatomical structure and the effects of reward (56-58). Medium spiny neurons (MSNs) from the NAc receive excitatory glutamatergic inputs and modulatory dopaminergic and cholinergic inputs from a variety of cortical and subcortical structures. The interaction between hippocampus and PFC
TABLE 2 | Distribution of excitatory amino acid transporters.

\begin{tabular}{lllll}
\hline $\begin{array}{l}\text { Types of } \\
\text { VGLUT }\end{array}$ & Majority distribution & Cell-type & $\begin{array}{l}\text { Target for } \\
\text { addiction }\end{array}$ & References \\
\hline EAAT1 & $\begin{array}{l}\text { Cerebellum (36) } \\
\text { Cortex (17) } \\
\text { Spinal cord (37) }\end{array}$ & Glial cells & Potential & (38) \\
EAAT2 & $\begin{array}{l}\text { Whole brain (17) } \\
\text { Spinal cord (37) }\end{array}$ & Glial cells & Potential & $(39)$ \\
EAAT3 & $\begin{array}{l}\text { Hippocampus } \\
\text { Cerebellum }\end{array}$ & Neuron & Yes & $(41)$ \\
& $\begin{array}{l}\text { Striatum (40) } \\
\text { EAAT4 }\end{array}$ & Cerebellum (40) & Neuron & Unknown \\
EAAT5 & Retina (42) & Photoreceptors Unknown & - \\
& & Bipolar cells & - \\
\hline
\end{tabular}

glutamate input is thought to provide synaptic plasticity in MSNs to regulate reward learning $(59,60)$. Although cholinergic neurons are a minority group of NAc neurons, their projection in MSN has been shown to control drug addiction (61-63). In the NAc, VGLUT3 participates in the cooperative release of glutamate from these cholinergic neurons $(64,65)$. VGLUT1 is mainly expressed in the cortical structure, and it has been shown that NAc receives glutamate input from PFC and hippocampus (66). The accumulation of glutamate in the presynaptic membrane is mainly through the VGLUTS. The VGLUTS family controls the release of glutamate by the presynaptic membrane of the neuron $(67,68)$. The expression of VGLUTS is closely related to the level of glutamate in the synaptic cleft. In particular, VGLUT3 is expressed on cholinergic intermediate neurons in NAc, which plays an important role in the function of NAc $(10,69)$. Because of the different expression patterns of VGLUTs, these proteins can be used as presynaptic markers to understand the input of glutamate into NAc. Tukey et al. suggested that chronic uptake of sucrose did not change the expression of VGLUT1 in the synaptoneurosomes of NAc. Repeated intake of sucrose resulted in an increase in the level of VGLUT2 and VGLUT3 subunits in the synaptoneurosomes of NAc (70). Another study proved that silencing VGLUT3 in mice resulted in cocaine induced locomotor activity significantly (71). In addition, Sakae et al. showed that knocking out VGLUT3 increased cocaine addiction by increasing the glutamate signals of the NAc (35). Thus, in the model of addiction, VGLUTS state a new signal form of synaptic plasticity in the NAc.

\section{The Role of GLT in Addiction in the PFC}

Projection neurons in the prefrontal cortex can regulate subcortical tissue structure, including ventral striatum and thalamus. Therefore, it can regulate the effects of addiction (72). Pyramidal neurons in the medial prefrontal cortex (mPFC) can receive nerves projections from different brain regions, including the basolateral amygdala. And at the same time, projection of glutamatergic neuron in the mPFC can also deliver to the VTA and NAc (73-75). In the limbic nervous system, including the prefrontal cortex, euphoria is associated with glutamate neurotransmission and the number of astrocytes. It is obvious 
that astrocytes regulate glutamate levels by removing glutamate from synapses by glutamate transporters. Glutamate neurons are mainly located in the prefrontal cortex. Studies have shown that the projection of glutamate neurons in the prefrontal cortex to the nucleus accumbens is an important rewarding pathway (76). VGLUT1 is mainly expressed in modulatory synapses, including PFC glutamate neurons project to the different brain regions of the reward circuit. Glutamate is the main driver of PFC neurons, and relapse to cocaine seeking requires the release of glutamate from the PFC projection to NAc (77). Glutamate transporter 1 (GLT-1) is responsible for the uptake of the majority of extracellular glutamate concentration (78, 79). Sari et al. showed that by upregulating the expression of glutamate transporter 1 blunts cue-induced reinstatement of cocaine-seeking behavior in rats (80). Their results suggested that glutamate played an important role in cue-induced relapse to cocaine-seeking behavior, implicating glutamate transporter 1 as a potential therapeutic target for cocaine addiction. Upregulating glutamate transporter 1 expression in mesocorticolimbic brain regions may serve as a potential treatment of drug addiction. The transmission of glutamate in synapse affects the excitability of neurons and the emotion. Drug abuse can lead to mood disorder. Therefore, to study the important role of glutamate transporter in the PFC is necessary and glutamate transporter may be a target to treat addiction.

\section{The Role of GLT in Addiction in the Hip}

Hippocampus is an important brain tissue related to information storage, which has many kinds of functions. The most important function of hippocampus is to store memory information and learning ability. Therefore, the synaptic plasticity of hippocampal neurons is considered to be related to learning and memory. Vesicular glutamate transporters (VGLUTs) play an important role in synaptic function by uptake of glutamate in vesicles at the presynaptic terminal $(81,82)$. VGLUT1 and VGLUT2 are a vesicular glutamate transporter commonly, which are found in the telencephalic region, such as hippocampus. Beside that, some studies has proved that VGLUT1 and VGLUT2 are co-location in the CA1 and CA3 region of the hippocampus (83). Neale et al. concluded that VGLUT inhibitors can regulate glutamatergic synaptic transmission in hippocampus (81). This may be important in the pathophysiology of neurological diseases and may represent the goal of developing new treatments to drug. In addition, a study proved that eliminating the VGLUT2-dependent glutamatergic transmission of parvalbumin-expressing neurons leads to deficits in locomotion (84). At the same time, deletion of VGLUT2 weakened the spatial learning and memory and synaptic plasticity in the hippocampus of mice (85). Some studies suggested that the synaptic responses of acute slice and autaptic cultured rat hippocampal neurons were significantly decreased in the VGLUT1 knock-out rat, suggesting that VGLUT1 was the main transporter subtype in this region $(86,87)$. Drug abuse will produce cue-induced drug seeking memory information stored in the hippocampus, which plays an important role in the reward system $(88,89)$. In addition, hippocampus is involved mediating reward-related learning (90). The concentration of glutamate in the hippocampus can affect the excitability of neurons. Therefore, VGLUTS are very important to maintain the balance of glutamic acid concentration in hippocampus. However, few studies have reported the role of VGLUTS in addiction, especially in hippocampus.

\section{The Role of GLT in Drug Addiction Induced by Different Kinds of Drug}

Addictive drugs can generally be divided into stimulants and inhibitors. For example, cocaine belongs to stimulants. Sakae et al. proved that knocking out VGLUT3 in the NAc aggravated cocaine-induced self-administration (35). In addition, Reissner et al. showed that propentofylline (PPF) restored the expression of glutamate transporter in the NAc induced by cocaine (91). Upregulation of glutamate transporter attenuates cocaineseeking behavior (80). Morphine is a kind of inhibitor drug targeting opioid receptor that can lead to addiction. Glutamate transporter is a crucial role in morphine dependence (13). Chronic morphine administration induced downregulation of glutamate transporter expression in the NAc (92). Besides, activation of glutamate transporter results in inhibiting morphine tolerance (13). In other word, drug addiction will result in the changes of glutamate transporter. These studies reveal that upregulation of glutamate transporter is a promising method for treating drug addiction. And it also suggests that glutamate transporter is involved in drug addiction induced by different kinds of Addictive drugs. However, the underlying mechanism is still unclear.

\section{SUMMARY}

VGLUTS are very important to maintain the balance of the glutamate concentration in different brain regions, thus, increasing the potential mechanisms to treat drug abuse. However, there is little study to investigate the role of VGLUTS in drug addiction. In this review, we suggest that the role of different types of VGLUTS in different brain regions in drug addiction shown in Figure 2. As we know, PFC, VTA, NAc, and Hip are crucial to reward system. Therefore, it is necessary to understand that how VGLUTS influence or get involved in drug addiction. Previous studies have proved that glutamate neurotransmitter plays an important role in drug addiction. Therefore, the release of glutamate from different brain regions via glutamate transporter also play a crucial role. In addition, it is worth studying the role of glutamate transporter in other diseases of the central nervous system, such as Parkinson's disease and Alzheimer's disease. In this review, we also find that whether glutamate transporters can be targets for drug addiction remains to be studied (Tables 1, 2). Although Sakae et al. showed that knocking out VGLUT3 aggravates cocaine-induced self-administration (35), the other kinds of transporter in different brain region are still unclear. For example, by interfering or upregulating the expression of Glutamate transporter in different brain regions, and detecting addictive behaviors by conditioned place preference or self-administration. Beside that, the role 


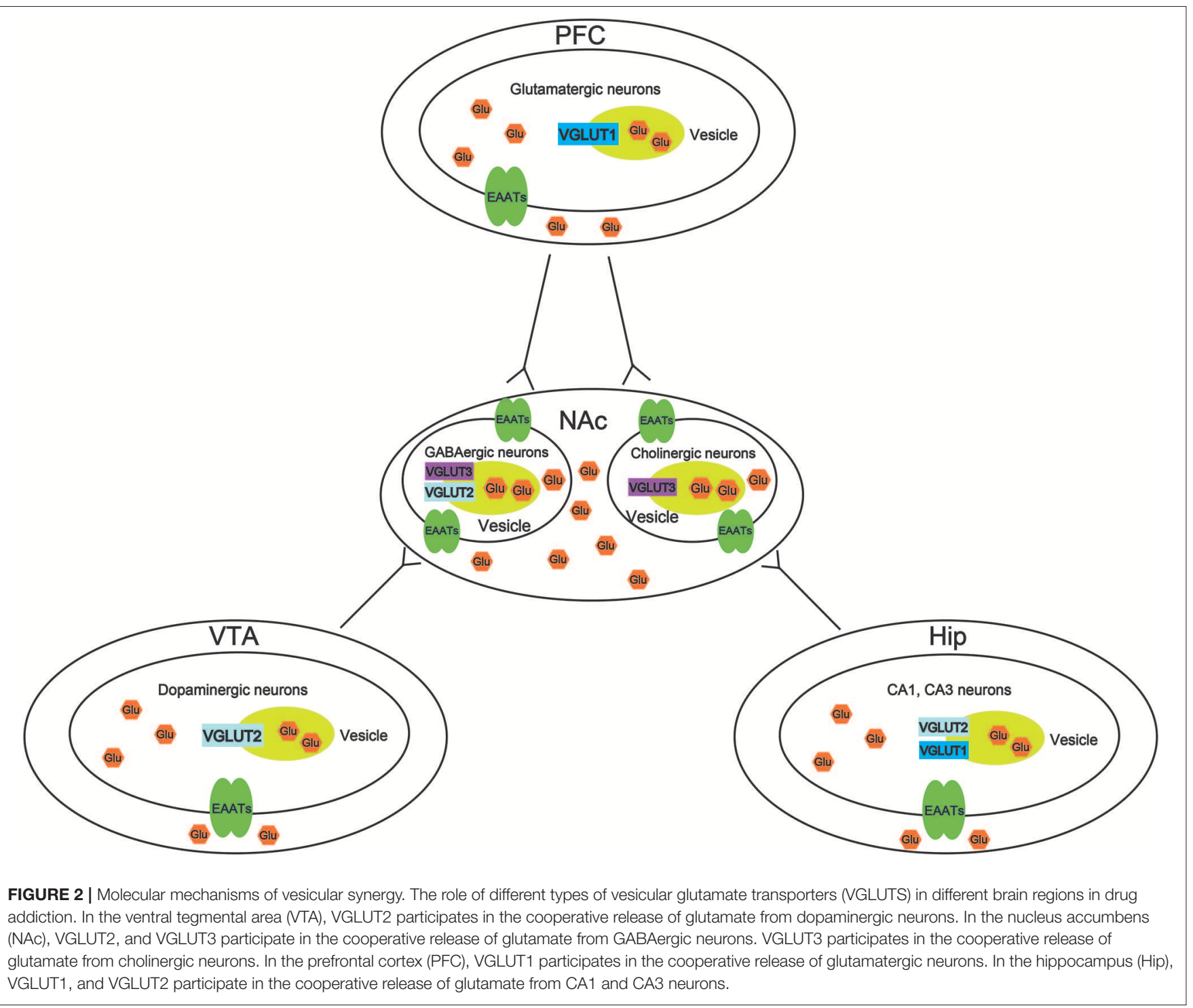

of glutamate transporter in relapse and withdrawal are also worth exploring. For example, by interfering or upregulating the expression of VGLUT in different brain regions, and detecting addictive behaviors by conditioned place preference. Some studies have proved that VGLUTS expression level influence the rate and extent of synaptic vesicle filling, and the probability of synaptic vesicle release (87, 93-95). Glutamate is the main excitatory neurotransmitter in the human brain. It has been proved that long-term activation of the glutamate system can lead to nerve injury and cell death. Herman et al. proved that a low probability of release of glutamate when VGLUT expression levels were decreased (93). It is important that the abnormal level of these VGLUTS have been found in the pathophysiology of mental disorders. Therefore, in the future, VGLUTS may be a new target for treating drug addiction.

\section{AUTHOR CONTRIBUTIONS}

XL was responsible for the study concept and design. WW and $\mathrm{YH}$ drafted the manuscript. XL and FZ provided a critical revision of the manuscript for important intellectual content. All authors read and approved the final version.

\section{FUNDING}

This work was funded by the undergraduate innovation and entrepreneurship training program (S201910727096).

\section{ACKNOWLEDGMENTS}

We thank to Elizabeth Rosalind for her significant corrections on the manuscript. 


\section{REFERENCES}

1. Nestler EJ. Molecular basis of long-term plasticity underlying addiction. Nat Rev Neurosci. (2001) 2:119-28. doi: 10.1038/35053570

2. Kauer JA, Malenka RC. Synaptic plasticity and addiction. Nat Rev Neurosci. (2007) 8:844-58. doi: 10.1038/nrn2234

3. Clark JD. Chronic pain prevalence and analgesic prescribing in a general medical population. J Pain Symptom Manag. (2002) 23:131-7. doi: 10.1016/S0885-3924(01)00396-7

4. Gretton SK, Ross JR, Rutter D, Sato H, Droney JM, Welsh KI, et al. Plasma morphine and metabolite concentrations are associated with clinical effects of morphine in cancer patients. J Pain Sympt Manage. (2013) 45:670-80. doi: 10.1016/j.jpainsymman.2012.03.015

5. Manchikanti L, Abdi S, Atluri S, Balog CC, Benyamin RM, Boswell MV, et al. American Society of Interventional Pain Physicians (ASIPP) guidelines for responsible opioid prescribing in chronic non-cancer pain: Part I-evidence assessment. Pain Phys. (2012) 15(3 Suppl.):S1-65.

6. Kalivas PW, Volkow ND. The neural basis of addiction: a pathology of motivation and choice. Am J Psychiatry. (2005) 162:1403-13. doi: 10.1176/appi.ajp.162.8.1403

7. Sesack SR, Grace AA. Cortico-basal ganglia reward network: microcircuitry. Neuropsychopharmacology. (2010) 35:27-47. doi: 10.1038/npp.2009.93

8. Gorelova N, Mulholland PJ, Chandler LJ, Seamans JK. The glutamatergic component of the mesocortical pathway emanating from different subregions of the ventral midbrain. Cereb Cortex. (2012) 22:327-36. doi: $10.1093 /$ cercor/bhr107

9. Hnasko TS, Hjelmstad GO, Fields HL, Edwards RH. Ventral tegmental area glutamate neurons: electrophysiological properties and projections. $J$ Neurosci. (2012) 32:15076-85. doi: 10.1523/JNEUROSCI.3128-12.2012

10. Mark GP, Shabani S, Dobbs LK, Hansen ST. Cholinergic modulation of mesolimbic dopamine function and reward. Physiol Behav. (2011) 104:76-81. doi: 10.1016/j.physbeh.2011.04.052

11. Rahman S, McBride WJ. Feedback control of mesolimbic somatodendritic dopamine release in rat brain. J Neurochem. (2000) 74:684-92. doi: 10.1046/j.1471-4159.2000.740684.x

12. Lievens JC, Bernal F, Forni C, Mahy N, Kerkerian-Le Goff L. Characterization of striatal lesions produced by glutamate uptake alteration: cell death, reactive gliosis, and changes in GLT1 and GADD45 mRNA expression. Glia. (2000) 29:222-32. doi: 10.1002/(SICI)1098-1136(20000201)29:3<222::AID-GLIA4>3.0.CO;2-0

13. Mao J, Sung B, Ji RR, Lim G. Chronic morphine induces downregulation of spinal glutamate transporters: implications in morphine tolerance and abnormal pain sensitivity. J Neurosci. (2002) 22:8312-23. doi: 10.1523/JNEUROSCI.22-18-08312.2002

14. Mennerick S, Shen W, Xu W, Benz A, Tanaka K, Shimamoto K, et al. Substrate turnover by transporters curtails synaptic glutamate transients. J Neurosci. (1999) 19:9242-51. doi: 10.1523/JNEUROSCI.19-21-09242.1999

15. Trotti D, Aoki M, Pasinelli P, Berger UV, Danbolt NC, Brown RH Jr, et al. Amyotrophic lateral sclerosis-linked glutamate transporter mutant has impaired glutamate clearance capacity. J Biol Chem. (2001) 276:576-82. doi: 10.1074/jbc.M003779200

16. Vorwerk CK, Naskar R, Schuettauf F, Quinto K, Zurakowski D, Gochenauer $\mathrm{G}$, et al. Depression of retinal glutamate transporter function leads to elevated intravitreal glutamate levels and ganglion cell death. Investig Ophthalmol Vis Sci. (2000) 41:3615-21.

17. Liu Y, Li C, Jia X, Huang L, Weiss JW. AMPA receptor dependent glutamatergic signaling is present in the carotid chemoreceptor. Neuroscience. (2018) 82:59-68. doi: 10.1016/j.neuroscience.2018.04.032

18. Hayashi MK. Structure-function relationship of transporters in the glutamateglutamine cycle of the central nervous system. Int J Mol Sci. (2018) 19:E1177. doi: 10.3390/ijms19041177

19. Zerangue N, Kavanaugh MP. Flux coupling in a neuronal glutamate transporter. Nature. (1996) 383:634-7. doi: 10.1038/383634a0

20. Wen ZH, Chang YC, Jean YH. Excitatory amino acid glutamate: role in peripheral nociceptive transduction and inflammation in experimental and clinical osteoarthritis. Osteoarthritis Cartil. (2015) 23:2009-16. doi: 10.1016/j.joca.2015.03.017
21. El Mestikawy S, Wallen-Mackenzie A, Fortin GM, Descarries L, Trudeau LE. From glutamate co-release to vesicular synergy: vesicular glutamate transporters. Nat Rev Neurosci. (2011) 12:204-16. doi: 10.1038/nrn2969

22. Navarro D, Alvarado M, Navarrete F, Giner M, Obregon MJ, Manzanares J, et al. Gestational and early postnatal hypothyroidism alters VGluT1 and VGAT bouton distribution in the neocortex and hippocampus, and behavior in rats. Front Neuroanat. (2015) 9:9. doi: 10.3389/fnana.2015.00009

23. Meves JM, Geoffroy CG, Kim ND, Kim JJ, Zheng B. Oligodendrocytic but not neuronal Nogo restricts corticospinal axon sprouting after CNS injury. Exp Neurol. (2018) 309:32-43. doi: 10.1016/j.expneurol.2018.07.013

24. Fang YY, Zeng P, Qu N, Ning LN, Chu J, Zhang T, et al. Evidence of altered depression and dementia-related proteins in the brains of young rats after ovariectomy. J Neurochem. (2018) 146:703-21. doi: 10.1111/jnc.14537

25. Erburu M, Munoz-Cobo I, Diaz-Perdigon T, Mellini P, Suzuki T, Puerta E, et al. SIRT2 inhibition modulate glutamate and serotonin systems in the prefrontal cortex and induces antidepressant-like action. Neuropharmacology. (2017) 117:195-208. doi: 10.1016/j.neuropharm.2017.01.033

26. Qi C, Guo B, Ren K, Yao H, Wang M, Sun T, et al. Chronic inflammatory pain decreases the glutamate vesicles in presynaptic terminals of the nucleus accumbens. Mol Pain. (2018) 14:1744806918781259. doi: $10.1177 / 1744806918781259$

27. Fattorini G, Ciriachi C, Conti F. Few, activity-dependent, and ubiquitous VGLUT1/VGAT terminals in rat and mouse brain. Front Cell Neurosci. (2017) 11:229. doi: 10.3389/fncel.2017.00229

28. Sun KL, Sillitoe RV, Silva C, Martina M, Sekerkova G. $\alpha$-Synuclein expression in the mouse cerebellum is restricted to VGluT1 excitatory terminals and is enriched in unipolar brush cells. Cerebellum. (2015) 14:1-12. doi: 10.1007/s12311-015-0673-9

29. Farris SP, Harris RA, Ponomarev I. Epigenetic modulation of brain gene networks for cocaine and alcohol abuse. Front Neurosci. (2015) 9:176. doi: 10.3389/fnins.2015.00176

30. Yamaguchi T, Sheen W, Morales M. Glutamatergic neurons are present in the rat ventral tegmental area. Eur J Neurosci. (2007) 25:106-18. doi: 10.1111/j.1460-9568.2006.05263.x

31. Azogu I, Plamondon H. Blockade of TrkB receptors in the nucleus accumbens prior to heterotypic stress alters corticotropin-releasing hormone $(\mathrm{CRH})$, vesicular glutamate transporter 2 (vGluT2) and glucocorticoid receptor (GR) within the mesolimbic pathway. Hormones Behav. (2017) 90:98-112. doi: 10.1016/j.yhbeh.2017.02.012

32. Brancato A, Bregman D, Ahn HF, Pfau ML, Menard C, Cannizzaro C, et al. Sub-chronic variable stress induces sex-specific effects on glutamatergic synapses in the nucleus accumbens. Neuroscience. (2017) 350:180-9. doi: 10.1016/j.neuroscience.2017.03.014

33. Papathanou M, Creed M, Dorst MC, Bimpisidis Z, Dumas S, Pettersson $\mathrm{H}$, et al. Targeting VGLUT2 in mature dopamine neurons decreases mesoaccumbal glutamatergic transmission and identifies a role for glutamate co-release in synaptic plasticity by increasing baseline AMPA/NMDA ratio. Front Neural Circuits. (2018) 12:64. doi: 10.3389/fncir.2018.00064

34. Herzog E, Gilchrist J, Gras C, Muzerelle A, Ravassard P, Giros B, et al. Localization of VGLUT3, the vesicular glutamate transporter type 3, in the rat brain. Neuroscience. (2004) 123:983. doi: 10.1016/j.neuroscience.2003. 10.039

35. Sakae DY, Marti F, Lecca S, Vorspan F, Martin-Garcia E, Morel LJ, et al. The absence of VGLUT3 predisposes to cocaine abuse by increasing dopamine and glutamate signaling in the nucleus accumbens. Mol Psychiatry. (2015) 20:1448-59. doi: 10.1038/mp.2015.104

36. Untiet V, Kovermann P, Gerkau NJ, Gensch T, Rose CR, Fahlke C. Glutamate transporter-associated anion channels adjust intracellular chloride concentrations during glial maturation. Glia. (2017) 65:388-400. doi: 10.1002/glia.23098

37. Schluter K, Figiel M, Rozyczka J, Engele J. CNS region-specific regulation of glial glutamate transporter expression. Eur J Neurosci. (2002) 16:836-42. doi: 10.1046/j.1460-9568.2002.02130.x

38. Šerý O, Sultana N, Kashem MA, Pow DV, Balcar VJJNR. GLAST but not least-distribution, function, genetics and epigenetics of 1 -glutamate transport in brain-Focus on GLAST/EAAT1. Neurochem Res. (2015) 40:112. doi: 10.1007/s11064-015-1605-2 
39. Jia YF, Choi YB, Ayers-Ringler JR, Biernacka JM, Veldic MJFiCN. Differential SLC1A2 promoter methylation in bipolar disorder with or without addiction. Front Cell Neurosci. (2017) 11:217. doi: 10.3389/fncel.2017.00217

40. Furuta A, Martin LJ, Lin CL, Dykes-Hoberg M, Rothstein JD. Cellular and synaptic localization of the neuronal glutamate transporters excitatory amino acid transporter 3 and 4. Neuroscience. (1997) 81:1031-42. doi: 10.1016/S0306-4522(97)00252-2

41. Wan L, Bi J, Li J, Zuo Z. Glutamate transporter type 3 participates in maintaining morphine-induced conditioned place preference. Neuroscience. (2017) 344:67-73. doi: 10.1016/j.neuroscience.2016.12.038

42. Schneider N, Cordeiro S, Machtens JP, Braams S, Rauen T, Fahlke C. Functional properties of the retinal glutamate transporters GLT-1c and EAAT5. J Biol Chem. (2014) 289:1815-24. doi: 10.1074/jbc.M113.517177

43. Addy NA, Nunes EJ, Wickham RJ. Ventral tegmental area cholinergic mechanisms mediate behavioral responses in the forced swim test. Behav Brain Res. (2015) 288:54-62. doi: 10.1016/j.bbr.2015.04.002

44. Dautan D, Souza AS, Huerta-Ocampo I, Valencia M, Assous M, Witten IB, et al. Segregated cholinergic transmission modulates dopamine neurons integrated in distinct functional circuits. Nat Neurosci. (2016) 19:1025-33. doi: $10.1038 / \mathrm{nn} .4335$

45. Han S, Yang SH, Kim JY, Mo S, Yang E, Song KM, et al. Down-regulation of cholinergic signaling in the habenula induces anhedonia-like behavior. $S c i$ Rep. (2017) 7:900. doi: 10.1038/s41598-017-16991-1

46. Yau HJ, Wang DV, Tsou JH, Chuang YF, Chen BT, Deisseroth K, et al. Pontomesencephalic tegmental afferents to VTA non-dopamine neurons are necessary for appetitive pavlovian learning. Cell Rep. (2016) 16:2699-710. doi: 10.1016/j.celrep.2016.08.007

47. Wang HL, Qi J, Zhang S, Wang H, Morales M. Rewarding effects of optical stimulation of ventral tegmental area glutamatergic neurons. J Neurosci. (2015) 35:15948-54. doi: 10.1523/JNEUROSCI.3428-15.2015

48. Kawano M, Kawasaki A, Sakata-Haga H, Fukui Y, Kawano H, Nogami H, et al. Particular subpopulations of midbrain and hypothalamic dopamine neurons express vesicular glutamate transporter 2 in the rat brain. J Comp Neurol. (2006) 498:581-92. doi: 10.1002/cne.21054

49. Tecuapetla F, Patel JC, Xenias H, English D, Tadros I, Shah F, et al. Glutamatergic signaling by mesolimbic dopamine neurons in the nucleus accumbens. J Neurosci. (2010) 30:7105-10. doi: 10.1523/JNEUROSCI.0265-10.2010

50. Sun X, Milovanovic M, Zhao Y, Wolf ME. Acute and chronic dopamine receptor stimulation modulates AMPA receptor trafficking in nucleus accumbens neurons cocultured with prefrontal cortex neurons. J Neurosci. (2008) 28:4216-30. doi: 10.1523/JNEUROSCI.0258-08.2008

51. Hyman SE, Malenka RC. Addiction and the brain: the neurobiology of compulsion and its persistence. Nat Rev Neurosci. (2001) 2:695-703. doi: $10.1038 / 35094560$

52. Birgner C, Nordenankar K, Lundblad M, Mendez JA, Smith C, Le GM, et al. VGLUT2 in dopamine neurons is required for psychostimulant-induced behavioral activation. Proc Natl Acad Sci USA. (2010) 107:389. doi: 10.1073/pnas.0910986107

53. Root DH, Mejias-Aponte CA, Qi J, Morales M. Role of glutamatergic projections from ventral tegmental area to lateral habenula in aversive conditioning. J Neurosci. (2014) 34:13906-10. doi: 10.1523/JNEUROSCI.2029-14.2014

54. Lammel S, Steinberg EE, Foldy C, Wall NR, Beier K, Luo L, et al. Diversity of transgenic mouse models for selective targeting of midbrain dopamine neurons. Neuron. (2015) 85:429-38. doi: 10.1016/j.neuron.2014. 12.036

55. Yoo JH, Zell V, Gutierrez-Reed N, Wu J, Ressler R, Shenasa MA, et al. Ventral tegmental area glutamate neurons co-release GABA and promote positive reinforcement. Nat Commun. (2016) 7:13697. doi: 10.1038/ncomms 13697

56. Heimer L, Zahm DS, Churchill L, Kalivas PW, Wohltmann C. Specificity in the projection patterns of accumbal core and shell in the rat. Neuroscience. (1991) 41:89-125. doi: 10.1016/0306-4522(91)90202-Y

57. Zahm DS, Brog JS. On the significance of subterritories in the "accumbens" part of the rat ventral striatum. Neuroscience. (1992) 50:751. doi: 10.1016/0306-4522(92)90202-D
58. Everitt BJ, Parkinson JA, Olmstead MC, Arroyo M, Robledo P, Robbins TW. Associative processes in addiction and reward. The role of amygdalaventral striatal subsystems. Ann NY Acad Sci. (2010) 877:412-38. doi: 10.1111/j.1749-6632.1999.tb09280.x

59. MacAskill AF, Little JP, Cassel JM, Carter AG. Subcellular connectivity underlies pathway-specific signaling in the nucleus accumbens. Nat Neurosci. (2012) 15:1624-6. doi: 10.1038/nn.3254

60. Britt JP, Benaliouad F, McDevitt RA, Stuber GD, Wise RA, Bonci A. Synaptic and behavioral profile of multiple glutamatergic inputs to the nucleus accumbens. Neuron. (2012) 76:790-803. doi: 10.1016/j.neuron.2012.09.040

61. Avena NM, Rada PV. Cholinergic modulation of food and drug satiety and withdrawal. Physiol Behav. (2012) 106:332-6. doi: 10.1016/j.physbeh.2012.03.020

62. de Rover M, Mansvelder HD, Lodder JC, Wardeh G, Schoffelmeer AN, Brussaard AB. Long-lasting nicotinic modulation of GABAergic synaptic transmission in the rat nucleus accumbens associated with behavioural sensitization to amphetamine. Eur J Neurosci. (2004) 19:2859-70. doi: 10.1111/j.0953-816X.2004.03370.x

63. Huang YH, Ishikawa M, Lee BR, Nakanishi N, Schluter OM, Dong Y. Searching for presynaptic NMDA receptors in the nucleus accumbens. $J$ Neurosci. (2011) 31:18453-63. doi: 10.1523/JNEUROSCI.3824-11.2011

64. Gras C, Herzog E, Bellenchi GC, Bernard V, Ravassard P, Pohl $\mathrm{M}$, et al. A third vesicular glutamate transporter expressed by cholinergic and serotoninergic neurons. J Neurosci. (2002) 22:5442-51. doi: 10.1523/JNEUROSCI.22-13-05442.2002

65. Schafer MK, Varoqui H, Defamie N, Weihe E, Erickson JD. Molecular cloning and functional identification of mouse vesicular glutamate transporter 3 and its expression in subsets of novel excitatory neurons. J Biol Chem. (2002) 277:50734-48. doi: 10.1074/jbc.M206738200

66. Wise RA, Bozarth MA. Brain mechanisms of drug reward and euphoria. Psychiatr Med. (1985) 3:445-60.

67. Wilson NR, Jiansheng K, Hueske EV, Tony L, Helene V, Murnick JG, et al. Presynaptic regulation of quantal size by the vesicular glutamate transporter VGLUT1. J Neurosci. (2005) 25:6221-34. doi: 10.1523/JNEUROSCI.3003-04.2005

68. Melo CV, Mele M, Curcio M, Comprido D, Silva CG, Duarte CB. BDNF regulates the expression and distribution of vesicular glutamate transporters in cultured hippocampal neurons. PLoS ONE. (2013) 8:e53793. doi: 10.1371/journal.pone.0053793

69. Tepper JM, Bolam JP. Functional diversity and specificity of neostriatal interneurons. Curr Opin Neurobiol. (2004) 14:685-92. doi: $10.1016 /$ j.conb.2004.10.003

70. Tukey DS, Lee M, Xu D, Eberle SE, Goffer Y, Manders TR, et al. Differential effects of natural rewards and pain on vesicular glutamate transporter expression in the nucleus accumbens. Mol Brain. (2013) 6:32. doi: 10.1186/1756-6606-6-32

71. Gras C, Amilhon B, Lepicard EM, Poirel O, Vinatier J, Herbin M, et al. The vesicular glutamate transporter VGLUT3 synergizes striatal acetylcholine tone. Nat Neurosci. (2008) 11:292-300. doi: 10.1038/nn2052

72. Vertes RP. Differential projections of the infralimbic and prelimbic cortex in the rat. Synapse. (2010) 51:32-58. doi: 10.1002/syn.10279

73. Gabbott PLA, Warner TA, Jays PRL, Salway P, Busby SJ. Prefrontal cortex in the rat: Projections to subcortical autonomic, motor, and limbic centers. J Comp Neurol. (2005) 492:145-77. doi: 10.1002/cne.20738

74. Hoover WB, Vertes RP. Anatomical analysis of afferent projections to the medial prefrontal cortex in the rat. Brain Struct Funct. (2007) 212:149-79. doi: 10.1007/s00429-007-0150-4

75. Mc VDO, Lubbers BR, Goriounova NA, Li KW, Rc VDS, Loos M, et al. Extracellular matrix plasticity and GABAergic inhibition of prefrontal cortex pyramidal cells facilitates relapse to heroin seeking. Neuropsychopharmacology. (2010) 35:2120-33. doi: 10.1038/npp.2010.90

76. Russo SJ, Nestler EJ. The brain reward circuitry in mood disorders. Nat Rev Neurosci. (2013) 14:609-25. doi: 10.1038/nrn3381

77. Mcfarland K, Lapish CC, Kalivas PW. Prefrontal glutamate release into the core of the nucleus accumbens mediates cocaine-induced reinstatement of drug-seeking behavior. J Neurosci Off J Soc Neurosci. (2003) 23:3531-7. doi: 10.1523/JNEUROSCI.23-08-03531.2003 
78. Tanaka K, Watase K, Manabe T, Yamada K, Watanabe M, Takahashi $\mathrm{K}$, et al. Epilepsy and exacerbation of brain injury in mice lacking the glutamate transporter GLT-1. Science. (1997) 276:1699-702. doi: $10.1126 /$ science.276.5319.1699

79. Rothstein JD, Dykes-Hoberg M, Pardo CA, Bristol LA, Jin L, Kuncl RW, et al. Knockout of glutamate transporters reveals a major role for astroglial transport in excitotoxicity and clearance of glutamate. Neuron. (1996) 16:67586. doi: 10.1016/S0896-6273(00)80086-0

80. Sari Y, Smith KD, Ali PK, Rebec GV. Upregulation of GLT1 attenuates cueinduced reinstatement of cocaine-seeking behavior in rats. J Neurosci. (2013) 29:9239-43. doi: 10.1523/JNEUROSCI.1746-09.2009

81. Neale SA, Copeland CS, Salt TE. Effect of VGLUT inhibitors on glutamatergic synaptic transmission in the rodent hippocampus and prefrontal cortex. Neurochem Int. (2014) 73:159-65. doi: 10.1016/j.neuint.2013.10.001

82. Siksou L, Silm K, Biesemann C, Nehring RB, Wojcik SM, Triller A, et al. A role for vesicular glutamate transporter 1 in synaptic vesicle clustering and mobility. Eur J Neurosci. (2013) 37:1631-42. doi: 10.1111/ejn.12199

83. Herzog E, Takamori S, Jahn R, Brose N, Wojcik SM. Synaptic and vesicular co-localization of the glutamate transporters VGLUT1 and VGLUT2 in the mouse hippocampus. J Neurochem. (2006) 99:1011-8. doi: 10.1111/j.1471-4159.2006.04144.x

84. Roccaro-Waldmeyer DM, Girard F, Milani D, Vannoni E, Pretot L, Wolfer DP, et al. Eliminating the VGlut2-dependent glutamatergic transmission of parvalbumin-expressing neurons leads to deficits in locomotion and vocalization, decreased pain sensitivity, and increased dominance. Front Behav Neurosci. (2018) 12:146. doi: 10.3389/fnbeh.2018.00146

85. He H, Mahnke AH, Doyle S, Fan N, Wang CC, Hall BJ, et al. Neurodevelopmental role for VGLUT2 in pyramidal neuron plasticity, dendritic refinement, and in spatial learning. J Neurosci. (2012) 32:15886-901. doi: 10.1523/JNEUROSCI.4505-11.2012

86. Fremeau RT Jr, Kam K, Qureshi T, Johnson J, Copenhagen DR, StormMathisen J, et al. Vesicular glutamate transporters 1 and 2 target to functionally distinct synaptic release sites. Science. (2004) 304:1815-9. doi: $10.1126 /$ science. 1097468

87. Wojcik SM, Rhee JS, Herzog E, Sigler A, Jahn R, Takamori S, et al. An essential role for vesicular glutamate transporter 1 (VGLUT1) in postnatal development and control of quantal size. Proc Natl Acad Sci USA. (2004) 101:7158-63. doi: 10.1073/pnas.0401764101

88. Li YJ, Ping XJ, Qi C, Shen F, Sun LL, Sun XW, et al. Re-exposure to morphineassociated context facilitated long-term potentiation in the vSUB-NAc glutamatergic pathway via GluN2B-containing receptor activation. Addict Biol. (2017) 22:435-45. doi: 10.1111/adb.12343

89. Taepavarapruk P, Phillips AG. Neurochemical correlates of relapse to d-amphetamine self-administration by rats induced by stimulation of the ventral subiculum. Psychopharmacology. (2003) 168:99-108. doi: 10.1007/s00213-002-1337-2

90. Rezayof A, Zarrindast MR, Sahraei H, Haeri-Rohani A. Involvement of dopamine receptors of the dorsal hippocampus on the acquisition and expression of morphine-induced place preference in rats. J Psychopharmacol. (2003) 17:415-23. doi: 10.1177/0269881103174005

91. Reissner KJ, Brown RM, Spencer S, Tran PK, Thomas CA, Kalivas PW. Chronic administration of the methylxanthine propentofylline impairs reinstatement to cocaine by a GLT-1-dependent mechanism. Neuropsychopharmacology. (2014) 39:499-506. doi: 10.1038/npp.2013.223

92. Ozawa T, Nakagawa T, Shige K, Minami M, Satoh M. Changes in the expression of glial glutamate transporters in the rat brain accompanied with morphine dependence and naloxone-precipitated withdrawal. Brain Res. (2001) 905:254-8. doi: 10.1016/S0006-8993(01)02536-7

93. Herman MA, Ackermann F, Trimbuch T, Rosenmund C. Vesicular glutamate transporter expression level affects synaptic vesicle release probability at hippocampal synapses in culture. J Neurosci. (2014) 34:11781-91. doi: 10.1523/JNEUROSCI.1444-14.2014

94. Moechars D, Weston MC, Leo S, Callaerts-Vegh Z, Goris I, Daneels $\mathrm{G}$, et al. Vesicular glutamate transporter VGLUT2 expression levels control quantal size and neuropathic pain. J Neurosci. (2006) 26:12055-66. doi: 10.1523/JNEUROSCI.2556-06.2006

95. Voglmaier SM, Kam K, Yang H, Fortin DL, Hua Z, Nicoll RA, et al. Distinct endocytic pathways control the rate and extent of synaptic vesicle protein recycling. Neuron. (2006) 51:71-84. doi: 10.1016/j.neuron.2006.05.027

Conflict of Interest: The authors declare that the research was conducted in the absence of any commercial or financial relationships that could be construed as a potential conflict of interest.

Copyright (C) 2019 Wang, Zeng, Hu and Li. This is an open-access article distributed under the terms of the Creative Commons Attribution License (CC BY). The use, distribution or reproduction in other forums is permitted, provided the original author(s) and the copyright owner(s) are credited and that the original publication in this journal is cited, in accordance with accepted academic practice. No use, distribution or reproduction is permitted which does not comply with these terms. 